\title{
Sarcopenia in Liver Transplantation: an Update
}

\author{
A. Dhaliwal ${ }^{1,2,3} \cdot$ F. R. Williams ${ }^{1,2,3} \cdot$ O. El-sherif $^{1} \cdot$ Matthew J. Armstrong ${ }^{1,3} \mathbb{C}$
}

Published online: 18 April 2020

(C) The Author(s) 2020

\begin{abstract}
Purpose of Review Patients undergoing liver transplantation (LT) are at high risk of sarcopenia and associated physical frailty. This review summarises advances in our knowledge of the definition, assessment, clinical implications and management of sarcopenia in LT.

Recent Findings Sarcopenia is associated with increased mortality, morbidity, physical disability and poor quality of life both before and after LT. Assessment tools have evolved from solely relying on imaging (i.e. muscle area only) to reproducible measures of function and physical performance status (i.e. liver frailty index). The multi-faceted management of sarcopenia is heavily reliant on nutrition (protein $>1.5 \mathrm{~g} / \mathrm{kg} /$ day) and exercise (combined aerobic and resistance) advice.

Summary There is an increased awareness of the clinical implications, assessment tools and management for patients with sarcopenia awaiting LT. Future studies need to investigate the role of specific nutritional supplements, pharmaco-/ behavioural therapy and the long-term outcomes (e.g. survival) of reversing sarcopenia in this patient population.
\end{abstract}

Keywords Frailty $\cdot$ Cirrhosis $\cdot$ Liver failure $\cdot$ Exercise $\cdot$ Nutrition $\cdot$ Muscle

\section{Introduction}

Over the past decade, there has been increased recognition of the importance of sarcopenia in patients with liver disease, in particular those with end-stage liver disease (ESLD) and those undergoing liver transplantation (LT). The prevalence ranges from 20 to $70 \%$ in these populations, with higher rates in men $[1,2]$. The definition of sarcopenia has evolved from the sole focus being on loss of skeletal muscle mass (via imaging) to the inclusion of muscle strength and function, which are commonly assessed by hand grip strength (HGS) and gait speed/ chair stands, respectively. The severity of sarcopenia, mainly

This article is part of the Topical Collection on Management of the Cirrhotic Patient

Matthew J. Armstrong mattyarm2010@googlemail.com

1 Liver Unit, Queen Elizabeth Hospital Birmingham, 3rd Floor, Nuffield House, Mindelsohn Way, Birmingham B15 2TH, UK

2 Institute of Inflammation and Ageing, University of Birmingham, Birmingham, UK

3 National Institute for Health Research, Birmingham Biomedical Research Centre at University Hospitals Birmingham NHS Foundation Trust, Birmingham, UK on cross-sectional imaging, is associated with increased mortality, morbidity, physical disability and poor quality of life both before and after LT [3, 4•]. Interestingly, measures of muscle strength (HGS) and function (including frailty indices incorporating chair stands and balance) have recently been shown to be independent predictors of mortality in ESLD and after LT, irrespective of the severity of the underlying liver disease $[5 \bullet, 6]$. This raises important questions in this cohort as to the pathogenesis of sarcopenia, its reversibility and what is the optimal therapeutic approach $[4 \bullet, 7,8 \bullet]$. The recognised causes for sarcopenia in ESLD are multi-factorial and largely revolve around a state of severe protein catabolism, poor nutritional intake, chronic inflammatory state and barriers to physical activity (fatigue, fluid retention, encephalopathy) (Fig. 1). However, with the exception of dietetic input and exercise advice, there is a paucity of established therapies. The only current curative treatment for ESLD remains LT, which is one of the single largest, surgical physiological stressors the human body encounters in modern day health care. Therefore, it remains paramount that we continue to increase our knowledge of the clinical assessment tools and therapeutic strategies surrounding sarcopenia in order to optimise the patient before and after LT. This review will focus on recent advances in our knowledge of sarcopenia and the future challenges in the setting of LT. 


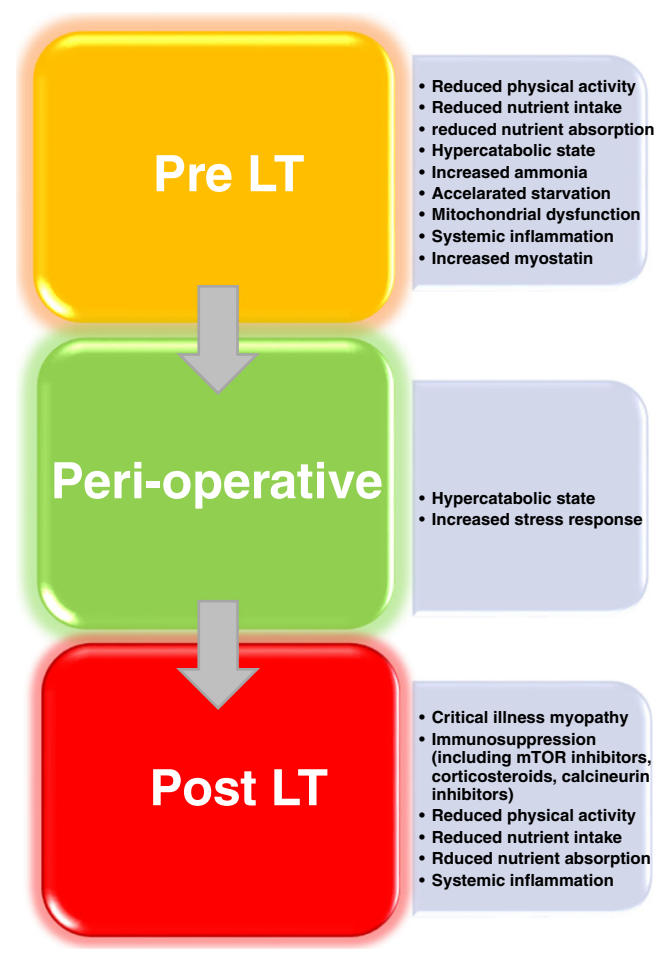

Fig. 1 Clinical factors contributing to sarcopenia pre-, peri- and post-liver transplantation (LT)

\section{Methods}

A literature search was performed using PubMed and Google Scholar to identify articles published from January 1, 2009, to December 31, 2019, using the following terms: 'sarcopenia', 'malnutrition', 'liver transplantation', 'end stage liver disease', 'muscle mass', 'muscle function', 'frailty', ' liver disease', 'liver cirrhosis'. Primary research articles, review articles, practice guidelines and editorials were included. Only articles published in English were used.

\section{Definition and Assessment of Sarcopenia}

One of the main challenges in the literature is the heterogeneity with regard to defining (i.e. cut-offs for skeletal muscle mass \pm function) and assessment tools for sarcopenia in patients awaiting or having undergone LT. The term was first described in 1989 to describe the process of skeletal muscle decline in the ageing population [9], and it is only in the last decade that the importance of muscle strength and/or function has been recognised [10]. The combination of low muscle mass and function to define sarcopenia first emerged from the European Working Group in Sarcopenia in Older People (EWGSOP) in 2010 [11]; however, due to the lack of defined cut-offs for these parameters, it has not been widely adopted. Tools to assess and diagnose sarcopenia have remained varied and inconsistent in both the literature and everyday clinical practice, with the field of LT being no exception $[12 \bullet \bullet]$. The vast majority of LT studies have retrospectively focused on measures of skeletal muscle mass alone using cross-sectional imaging $[13,14]$, with only a handful of reports focusing on muscle (hand-grip) strength [8・,15].

\section{Assessment of Muscle Mass}

The most frequently used measure of muscle mass in patients with ESLD and after LT is skeletal muscle index (SMI) of the L3 lumbar level on CT. This is largely due to the increasingly, routine use of abdominal CT imaging as part of the LT assessment and for the investigation of post-LT complications [16]. In 2016, a large meta-analysis (19 studies), consisting of 3802 patients awaiting or undergoing LT, investigated the utility of CT assessed skeletal muscle as a predictor of LT morbidity and mortality. In the recognition that there was significant study heterogeneity (sample size, imaging, muscle type, liver disease severity), overall sarcopenia was associated with both pre- (HR 1.7) and post-LT (HR 1.8) mortality and to a lesser extent complications, including infection [14]. Due to a lack of standardised definition of sarcopenia and specific sexdefined cut-offs in these studies, widespread application to routine clinic practice has been challenging. However, the recent formation of the North American FLEXIT (Fitness, Life Enhancement and Exercise in Liver Transplantation) Consortium has resulted in validated cut-offs for SMI at L3 to define sarcopenia in ESLD; namely $<50 \mathrm{~cm}^{2} / \mathrm{m}^{2}$ in men and $<39 \mathrm{~cm}^{2} / \mathrm{m}^{2}$ in women. Sex-specific cut-offs of SMI correlated with LT waiting list mortality [17, 18], but the same was not true for psoas muscle evaluation (in the form of psoas muscle index [PSI]), which particularly underestimated clinical impact in males [19]. It is important to recognise the setting when applying SMI. For example, in patients with high modified end-stage liver disease (MELD) scores and with acute deterioration, low SMI resulted in 4-fold increased risk of post-LT mortality in men (SMI $\left.<48 \mathrm{~cm}^{2} / \mathrm{m}^{2}\right)$, but in contrast, no differences were seen in women [20•]. Furthermore, a large cohort of 669 patients with cirrhosis highlighted that adding SMI onto the MELD (termed 'MELD-sarcopenia') improved the predictive accuracy of mortality, especially in those with a low MELD under 20 [21]. Other modalities for assessing muscle mass include bioelectrical impedance analysis (BIA) and dual-energy X-ray absorptiometry (DEXA). In general, these are cheaper, safe, reproducible, time efficient and offer less radiation exposure compared to CT [22]. However, their use is restricted in individuals with fluid retention (i.e. ascites, anasarca) due to their inability to distinguish water from muscle and in limited studies they have not been shown to be as accurate as CT imaging [23].

Even though CT assessment of muscle area is reproducible and accurate in patients with ESLD, it is hard to justify the cost and repeated radiation exposure to monitor response to treatment (i.e. nutrition), with exception of imaging requested for 
other clinical indications (i.e. cancer monitoring, vasculature patency). Anthropometry and more specifically mid-arm muscle circumference (MAMC) is cheap and can be safely used in out-patients to assess repeated measures of muscle mass. When performed by trained individuals, MAMC has good intra-/inter-observer agreement [24] and has been shown to predict mortality in patients with cirrhosis and those after LT [25]. Surprisingly, some studies have shown that MAMC poorly correlates with CT and MRI. In addition to MAMC, targeting specific muscle groups (i.e. quadriceps, and in particular vastus lateralis) with ultrasound have shown promise in the elderly population [12••, 26] and in isolated LT studies [1]. Ultrasound is accessible (i.e. performed by the bedside), sequential monitoring is not limited by radiation exposure, and has the ability to detect subtle changes of sarcopenia in the vastus lateralis. The latter of which may enable early identification and targeted intervention. Even though it has high reported levels of inter- and intra-observer reliability [1], its reproducibility in the setting of LT remains unknown.

The LT literature at present is still lacking evaluation of muscle mass in different ethnicities (i.e. majority of data from North America and the Far East) and rarely accounts for the gender disparity in sarcopenia (mortality: male>female) [27] (Table 1). Furthermore, the evolving prevalence of sarcopenia in parallel with the epidemic of obesity (termed 'sarcopenic obesity') poses a significant challenge in the field of LT, with rates of 20-40\% reported in patients awaiting LT [28•, 29]. The majority of the literature on the impact of sarcopenic obesity on LT is provided by the living-donor LT experiences, in which patients with sarcopenic obesity have worse 1-year post-LT survival than those with non-sarcopenic obesity $(54 \%$ vs $84 \%$ ) [30]. There remains a paucity of data in patients with a body mass index $(\mathrm{BMI})>35-40 \mathrm{~kg} / \mathrm{m}^{2}$, in whom sarcopenia may go unrecognised using measures of muscle mass alone in the absence of functional/physical assessments.

\section{Assessment of Muscle Strength}

HGS (non-dominant hand) is the most readily used assessment of muscle strength due to the fact it is easy to perform, can be serially measured to assess progression/regression and has the strongest evidence base in ESLD. Subsequently, HGS is currently recommended by both recent international guidelines (European Association of Study of Liver (EASL); European Society for Clinical Nutrition and Metabolism (ESPEN)) in the assessment of all patients with cirrhosis and liver failure $[31 \bullet \bullet, 32 \bullet \bullet$. HGS has been shown to be a better predictor of adverse clinical outcomes than measures of muscle mass [33] and MELD [8•]. It can represent a quick, bedside global assessment of muscle strength in patients with ESLD as it correlates strongly with lower extremity muscle power [34]. In a recent North American study of 145 male patients undergoing LT assessment, an increase in $1 \mathrm{~kg}$ of HGS was associated with a $6 \%$ reduction in mortality, independent of the baseline MELD [8•]. In combination with MELD, HGS was significantly superior to MELD + CT muscle mass in predicting transplant-free survival on the LT waiting list [8•]. This however would need to be reproduced in a female population.

\section{Assessment of Muscle Function and Physical Performance}

Various simple, cheap, non-invasive assessments of muscle function and physical 'functional' ability exist that can be performed either by the patient's bedside or at their outpatient clinic appointment (Table 1). To date, the main physical 'functional' performance measures that have been described in patients awaiting LT, include Karnofsky Performance Status (KPS) [1, 35], Activities of Daily Living (ADL) scale [36•, 37], Short physical performance battery (SPPB) [38], 6-min walk test (6MWT, also referred to as 6MWD(distance)) [39, 40], gait speed [41] and cardiopulmonary exercise test (CPET) $[42,43]$. A detailed description of the above has been summarised in an expert opinion statement by the American Society of Transplantation Liver and Intestinal Community of Practice $[12 \bullet \bullet]$.

With the exception of CPET, the other measures are cheap, easy-to-access and can be performed in seconds to minutes. The SPPB, which consists of chair stands, gait speed and balance (each scored out of 4; total 12), is associated with overall mortality in LT, with a cut-off $<10$ increasing the odds of mortality by 2.5 [44]. It is, however, limited in patients with higher levels of baseline physical function (SPBB 12 out of 12 ), as it has a ceiling score of 12 , which means interventions may be overlooked in these individuals. In contrast, the $6 \mathrm{MWT}$ does not a have a ceiling effect, as it is a continuous scale of distance based on a sub-maximal exercise test used to assess aerobic capacity. In the last 5 years, cut-offs of distance have been described in relation to all-cause mortality $[39,40]$. The largest study to date of 213 out-patients with ESLD awaiting LT highlighted that a distance of $<250 \mathrm{~m}$ resulted in a 2-fold increased risk of mortality [40]. Unlike these 'easyto-perform' tests, CPET requires specialist expertise and expensive equipment (cyclometer or treadmill) [45]. In 2016, Ney and colleagues performed a systematic review of 7 studies consisting of over 1000 patients and highlighted that CPET variables (most notably peak $\mathrm{VO}_{2}$ and anaerobic threshold [AT]) were independent predictors of pre-LT and post-LT mortality [42]. The majority of these studies are retrospective in design and are limited by selection-bias, in that those with a low aerobic exercise capacity may have been declined listing for LT and thus their outcomes remain unknown. It is also important to highlight that no single cut-off for AT or $\mathrm{VO}_{2}$ peak should be used in isolation to determine a patient's physical fitness for LT. If CPET is utilised it should be taken in context with the patients ADLs, disease severity, co- 
Table 1 Overview of measures and interventions of sarcopenia in LT. These are the views of the authors only based on the quality of the published data available in patients end-stage liver disease and undergoing LT. Key: unless stated: US, United States; MTORC1, mammalian target of rapamycin complex 1; DEXA, dual-energy X-ray absorptiometry

\begin{tabular}{|c|c|c|c|}
\hline & Validated measures & Controversies & Future research targets \\
\hline Mass & $\begin{array}{l}\text { Computed tomography } \\
\text { abdominal imaging } \\
\text { (especially lumbar } 3 \text { ) } \\
\text { Mid-arm muscle circumference } \\
\text { (MAMC) } \\
\text { Magnetic resonance imaging } \\
\text { (limited studies) }\end{array}$ & $\begin{array}{l}\text { DEXA imaging } \\
\text { Bioimpedance analysis }\end{array}$ & $\begin{array}{l}\text { Validating muscle ultrasound (quadriceps) } \\
\text { Ethnic diversity of study populations } \\
\text { Sarcopenic obesity }\end{array}$ \\
\hline Physical function/frailty & $\begin{array}{l}\text { 6-min walk test (6MWT) } \\
\text { Short performance battery } \\
\quad \text { (SPBB) } \\
\text { Liver frailty index (LFI) } \\
\text { Hand grip strength (HGS) }\end{array}$ & $\begin{array}{l}\text { Gait speed alone } \\
\text { Cardio-pulmonary exercise } \\
\text { testing (CPET) }\end{array}$ & $\begin{array}{l}\text { Validating LFI in non-US countries } \\
\text { Understanding accuracy of sequential } \\
\text { measures/response to intervention }\end{array}$ \\
\hline & Validated treatments & Controversies & Future research targets \\
\hline Nutrition/pharmacology & $\begin{array}{l}\text { Protein requirements between } \\
1.5-2 \mathrm{~kg} / \mathrm{kg} / \mathrm{day} \\
\text { Caloric intake } \\
30-40 \mathrm{kcal} / \mathrm{kg} / \text { day } \\
\text { Minimal fasting times } \\
\text { of } 2-3 \mathrm{~h}\end{array}$ & $\begin{array}{l}\text { Hypocaloric diet of } \\
\quad(500-800 \mathrm{kcal} / \text { day) for } \\
\text { sarcopenic obesity } \\
\text { Type of protein supplement } \\
\text { (vegetable vs. animal protein) } \\
\text { Direct effect of hormone } \\
\text { (testosterone)/vitamin (D) } \\
\text { replacement }\end{array}$ & $\begin{array}{l}\text { Nutrition before and after exercise } \\
\text { Optimal contents of night time snack } \\
\text { Use of ammonia-lowering therapies (e.g. rifaximin) } \\
\text { Novel direct therapies: Vitamin D, Myostatin inhibitors, } \\
\text { MTORC1 activators, branch-chain amino acids } \\
\text { (BCAA) }\end{array}$ \\
\hline Exercise & $\begin{array}{l}\text { Personalised resistance and } \\
\text { aerobic exercise programmes }\end{array}$ & $\begin{array}{l}\text { Adherence to exercise } \\
\text { programmes } \\
\text { Type, frequency and intensity } \\
\text { of exercise }\end{array}$ & $\begin{array}{l}\text { Behavioural and psychological/motivation therapy } \\
\text { Home-based vs. supervised }\end{array}$ \\
\hline
\end{tabular}

morbidities and other markers of sarcopenia. Of note, the Duke Activity Index (DASI) questionnaire, which takes less than 5 min to complete, has been shown to be a better predictor of death or major cardiac events than CPET in patients undergoing major non-cardiac surgery [46•]. Future studies should aim to evaluate if this holds true for those undergoing LT, as not only would this reduce costs and clinician time, but could be assessed virtually in order to begin optimising those 'at risk' before assessing them at the tertiary care LT centres.

Most recently the North American Expert Opinion statement on sarcopenia have issued their rationale of using muscle mass alone to define sarcopenia, whilst incorporating muscle dysfunction in their definition and concept of 'frailty' [12••]. Certainly, the field has moved towards a global assessment of muscle strength and functional ability, using easy-to-perform tests, rather than CT-muscle mass alone in order to evaluate and predict the outcome of patients undergoing LT.

\section{The Evolution of the LFI) in LT}

Frailty is a multi-dimensional construct (physical, psychological, environmental/social components) that combine to define a clinical state of decreased physiologic reserve and increased vulnerability to health stressors [47]. Physical frailty is the component that has most frequently been described in LT since 2014 and encompasses muscle mass/strength (i.e. sarcopenia), functional capacity (i.e. ability to complete ADLs) and aerobic exercise capacity (i.e. ability to utilise oxygen during physical exertion) [48•]. In order to capture an accurate, quick, objective assessment of muscle strength and function (i.e. 2 key components of physical frailty) Lai and colleagues devised the 'Liver Frailty Index (LFI)' in 2017 from a cohort of 536 patients with ESLD [49••]. Using the concept of the well-known Fried Frailty Index [47] and the SPPB [50], the LFI consists of dominant HGS, time to do 5 chair stands and time holding 3 balance positions (feet side by side, semi-tandem and tandem). Importantly, LFI is a liver disease-specific, continuous variable (i.e. no ceiling or floor effect) that can then be categorised into frail, pre-frail and robust and assessed longitudinally. Over the last 3 years, the LFI has been shown to be a good predictor of LT waiting list mortality (independent of MELD-sodium, ascites, encephalopathy), hospital admissions and post-LT mortality and most recently rates of acute cellular rejection [5•, 49••, 51-53]. There is a pressing need to validate the LFI in non-US countries, in the acutely unwell (i.e. acute-on-chronic liver failure), inpatients and for studies to assess its dynamic ability to assess response to nutritional/exercise interventions. In doing so, 
indexes such as LFI could be used as a standard tool in all LT units to facilitate clinical comparisons. It is, however, important to emphasise that there is no data to support a single frailty cut-off at which a patient should not undergo LT [54•].

\section{Impact of Sarcopenia in LT}

Sarcopenia, regardless of how it is measured or whether it is defined within physical frailty, is a strong predictor of clinically significant adverse outcomes before LT including: poor quality of life [55], hepatic decompensation [56] (including hepatic encephalopathy [57]), infection [58] and mortality $[14,21,38,59]$. It also predicts outcomes after LT as patients with sarcopenia have a longer hospital stay, need for mechanical ventilation, intensive care, an increased risk of infection, higher health care costs and an increased 1-year mortality post LT $[2,6,20 \bullet, 51,53,58,60,61]$.

Graft choice is determined by the pre-LT assessment of the patient (i.e. age, disease severity, co-morbidities, surgical history) and is an integral part of a successful outcome post-LT. Interestingly, a UK-based study of 232 consecutive LTs highlighted that of those who received a marginal graft (i.e. steatotic, cold ischaemia time $>12 \mathrm{~h}$ ) the patients with malnutrition (as determined by the Royal Free Hospital-Global Assessment tool) or muscle mass depletion (L3 on CT imaging) had significantly higher rates of infection and intensive care/hospital length of stays; irrespective of their baseline MELD [6]. Even though this requires further validation, it highlights the importance of careful graft selection in patients with sarcopenia or the need to re-evaluate graft choice after a period of nutritional optimisation.

\section{Management of Sarcopenia: a Multi-faceted Approach}

Unlike other risk factors associated with LT (i.e. age, MELD, sex, donor type), sarcopenia and its counterparts of physical frailty (malnutrition, poor functional status) are potentially modifiable with lifestyle, nutrition, exercise and pharmacotherapy $[31 \bullet \bullet, 32 \bullet, 48 \bullet, 62-65]$. Even though it's a hugely neglected area in LT, incorporation of behavioural/ psychological therapies alongside nutrition and exercise advice, are likely to be key in motivating the patient, overcoming their own personal/social barriers and maximising healthcare engagement. Therefore, a multidisciplinary team (MDT) assessment and approach is integral in order to fully optimise the muscle health and physical 'functional' performance status of a patient, both before (prehabilitation) and after (rehabilitation) LT $[48 \bullet, 54 \bullet, 63]$. Despite advances in recognition that sarcopenia and physical frailty result in adverse outcomes in ESLD and LT, there remains very little data that improving muscle mass \pm function increases survival pre- and post-LT $[66,67]$. This is largely due to a lack of robust prospective studies in this field and the multi-factorial complexity of this patient group (Table 1).

\section{Lifestyle}

All patients with ESLD and those on the LT waiting list, irrespective of aetiology, should be advised to abstain from alcohol and smoking. This is even more paramount in the 'frailer' patient as a result of the compound effect of ethanol and/or smoking has on sarcopenia $[68,69]$. It is also important to optimise glycaemic control in patients with glucose intolerance and type 2 diabetes in the setting of LT, as it is an integral part of preventing and potentially reversing sarcopenia. Insulin resistance and the resultant hyperinsulinaemic state not only drive fat accumulation in the muscle (myosteatosis), but also reduce protein synthesis and increase catabolism, which together drive sarcopenia [57]. This is particularly pertinent in the immediate post-LT setting, as the standard inclusion of prednisolone in the immunosuppression regimen, not only promotes hyperglycaemia but the debilitating early-onset (atrophic) effects of glucocorticoids in the muscle are well known [70].

\section{Nutrition}

The imbalance of increased muscle protein catabolism and reduced protein synthesis occurs in patients with ESLD due to a number of nutritional factors, including; an increased catabolic state, reduced nutrient absorption and decreased caloric/protein intake (i.e. early satiety, anorexia, nausea, encephalopathy) [71, 72]. Daily intake of total calories, proteins and carbohydrates is inadequate in approximately $85-95 \%$ of patients referred for LT assessment [73]. All patients undergoing assessment for LT, and ideally at the point of diagnosis of ESLD, should undergo a comprehensive nutritional evaluation in the form of anthropometry (MAMC, HGS, tricep skin fold thickness, calculated dry BMI) and accurate analysis of food intake. The latter remains a challenge and has been a rather neglected area of research in the last 5 years. To date, several tools have been developed to assess food intake, including the 2-day, 3-day and 7-day food diaries, the Food Frequency Questionnaire (FFQ), and the $24 \mathrm{~h}$ recall. However, it still remains unclear in the literature which tool is the most accurate as a result of limitations in reproducibility, clinical availability and inaccurate reporting (especially in patients susceptible to encephalopathy). International guidelines, as recent as 2019, are however consistent in their recommendations that an individual's caloric and protein requirements must be met by frequent feeding, oral dietary supplementation and/or when indicated by (par) enteral routes $[31 \bullet \bullet, 32 \bullet \cdot]$. The latter is particularly important in patients hospitalised with acute deterioration, who are unlikely to meet their caloric requirements. 
In non-obese patients (based on estimated dry body weight) the recommended daily caloric intake is at least $35 \mathrm{kcal} / \mathrm{kg} /$ day, whereas this should be cautiously reduced by $500-$ $800 \mathrm{kcal} /$ day in patients with sarcopenic obesity, in order to promote reduction in excess adiposity [31••]. The precise caloric target to achieve this effectively and safely (i.e. losing adipose mass whilst preserving/ improving muscle mass) remains unresolved [32••]. This is therefore a critical research question moving forwards, especially in light of the rising prevalence of NAFLD and its co-existing metabolic syndrome in patients referred for LT [74]. One of the most influential nutritional changes in advice over the last decade has been the switch from active protein restriction [75] to the consistent need to obtain high levels of protein intake, irrespective of the severity of encephalopathy $[31 \bullet \cdot, 32 \bullet \cdot]$. The protein target recommended is $1.5 \mathrm{~g} / \mathrm{kg} /$ day, with this increasing up to $2.0 \mathrm{~g} / \mathrm{kg} /$ day in cases of severe hepatic decompensation (e.g. high MELD, regular paracentesis for refractory ascites) [31 • $]$. The decision to formally advise vegetable-based (rich in branched chain amino acids (BCAA)) over animal-based protein (rich in aromatic amino acids [AA]) intake still requires further research. However, there does appear to be a rationale argument for avoiding amino acids that are not metabolised by muscle (i.e. aromatic AAs may promote encephalopathy) and targeting those that reduce serum ammonia (i.e. BCAA via glutamate-glutamine pathway) [76].

Patients with ESLD have 'accelerated starvation' and are susceptible to rapid muscle catabolism with prolonged periods of fasting. Therefore, a regular eating pattern of 2-3 hourly meals and snacks should be encouraged, with emphasis on the importance of not missing breakfast after an overnight fast [72]. Although the optimal snack content is not defined in the literature, a late-evening snack/before bedtime is recommended, with $50 \mathrm{~g}$ carbohydrate and up to $20 \mathrm{~g}$ protein commonly utilised [77].

\section{Exercise}

Over the last 5 years, there has been a drive to reverse physical frailty and improve physical function/exercise capacity in patients awaiting LT. Indeed, in 2014 the American Society for Transplantation set out a clear research agenda for exercise interventions in patients awaiting solid-organ transplantation [78]. The application of exercise training in patients awaiting LT has previously lagged behind that of other forms of solidorgan transplantation (i.e. lung, heart), which in part may have been due to anxieties surrounding acute increases in portal pressures and the potential for variceal haemorrhage [79]. Reassuringly, however the Italian SportDiet study of 50 patients with compensated cirrhosis highlighted that 16-weeks diet and exercise intervention was both safe and significantly reduced portal pressures [80॰]. To date, eleven studies (5 RCT, 5 observational, 1 case report) have demonstrated that exercise improves anaerobic thresholds, peak $\mathrm{VO}_{2}, 6 \mathrm{MWD}$, muscle mass/function and to a certain extent quality of life in patients with compensated and decompensated cirrhosis [62, 81-83]. None of these studies investigated survival benefit and the majority were small (1-50 patients), focus on supervised, hospital-based aerobic exercise interventions (i.e. cycle ergometer) and largely excluded patients requiring a LT (i.e. MELD > 12) [48•, 63, 84].

Large geographical areas, impractical travel times and costs, ill health and family and/or work obligations tend to limit the applicability of supervised (2-3× weekly) hospitalbased exercise interventions in patients awaiting LT [48•]. In light of these limitations, recent studies (albeit small pilot studies) have focused on the safety, feasibility and efficacy of home-based exercise programmes in patients awaiting LT $[65,84,85]$. In particular, one UK-based study $(n=18)$ highlighted safety, compliance and improvements in physical function (SPPB, daily step count, shuttle walk testing) whilst on the LT waiting list, following a 12-week home-based combined aerobic (walking) and body-weight resistance exercises (no additional equipment) [84]. Even though large RCTs are still required, in general, a combination of a minimum of 12 weeks of aerobic (3 days/week) and resistance exercises ( 2 days/week), performed at moderate-high intensity, should be recommended to optimise muscle health and physical performance status whilst awaiting LT [48 $]$. Ideally, programmes should be easily accessible (ideally home-based) and focus on each individual's barriers to exercise and baseline physical frailty. Further research is also required to guide nutritional replacement both before and after exercise, as this data is currently lacking in patients with ESLD.

Following LT, several rehabilitation studies have demonstrated that predominantly supervised (only one home-based) aerobic exercise improves measures of sarcopenia, exercise capacity and reported to a lesser degree - quality of life [86, $87 \cdot, 88]$. Similarly to the pre-LT setting, these studies are small and heterogenous (timing, type, intensity), but highlight that combined aerobic and resistance exercises yield the most promising improvements.

\section{Pharmacotherapy}

Pharmacotherapy is another promising research area in sarcopenia, with potential targets in including micronutrients, vitamin D [89], ammonia-lowering treatments [90], hormonal therapy (i.e. testosterone replacement in males [91•]) and Lcarnitine (an amino acid required for fatty acid oxidation, reported to suppress muscle loss) [92]. In particular, there has been a lot of pre-clinical interest in myostatin antagonists [93] and direct mammalian target of rapamycin complex 1 (mTORC1) [94] activators, which play key roles in protein synthesis and skeletal muscle mass. In particular, myostatin is a protein member of the transforming growth factor- $\beta$ 
(TGF- $\beta$ ) superfamily, which is produced and released by myocytes and in turn inhibits muscle cell growth and differentiation. Even though the provisional murine/primate studies have highlighted that myostatin antagonism results in increased muscle mass and performance, these interventions are likely to require extensive 'mechanistic' pre-clinical study and reproducible human clinical trials before they can be applied to routine clinical practice [93]. An extensive overview of future pharmacotherapy targets is summarised elsewhere $[4 \cdot]$.

\section{Summary}

Patients with ESLD are for a multitude of factors at high risk of sarcopenia and physical frailty beyond their years of life. CT-confirmed sarcopenia and clinical measures of physical frailty have been shown to be strong predictors of adverse clinical outcomes and premature mortality; often independently to the severity of the liver disease itself. The clinicians' ability to provide an objective assessment of the 'frail' liver patient in the out-patient setting has been significantly advanced with the emergence of easy-to-perform indices of frailty (e.g. LFI). However, further research is required to understand the use of these tools as sequential measures of clinical deterioration and/or response to multi-faceted interventions, such (p)rehabilitation. Robust international 'nutrition' guidelines now exist for patients with ESLD, with specific emphasis on high protein intake and 2-3 hourly food intake to minimise periods of fasting. In parallel, evidence (albeit small sample sizes) has emerged regarding the safety and efficacy of aerobic and resistance-based exercises in patients with ESLD, whom were previously felt to be too high risk to partake. Larger RCTs are required to consolidate these findings and investigate the optimal type, frequency and intensity of aerobic and resistance exercises. Future research also needs to focus on specific behavioural/motivational techniques, additional nutritional/micronutrients supplements (i.e. before/after exercise, late-night snack contents) and novel pharmacotherapies in order to maximise the physical conditioning and reserve of patients awaiting or recovering from LT.

Author Contributions $\mathrm{AD}$ and MJA developed the concept, performed the literature search and wrote the first draft. MJA, AD, FW and OES edited and approved the final manuscript.

Funding Information No financial support applicable to this manuscript. The views expressed are those of the authors and not necessarily those of the NHS, the National Institute for Health Research (NIHR) or the Department of Health.

\section{Compliance with Ethical Standards}

Conflict of Interest The authors declare that they have no conflict of interest.
Human and Animal Rights and Informed Consent All reported studies/ experiments with human or animal subjects performed by the authors have been previously published and complied with all applicable ethical standards (including the Helsinki declaration and its amendments, institutional/national research committee standards, and international/national/institutional guidelines).

Open Access This article is licensed under a Creative Commons Attribution 4.0 International License, which permits use, sharing, adaptation, distribution and reproduction in any medium or format, as long as you give appropriate credit to the original author(s) and the source, provide a link to the Creative Commons licence, and indicate if changes were made. The images or other third party material in this article are included in the article's Creative Commons licence, unless indicated otherwise in a credit line to the material. If material is not included in the article's Creative Commons licence and your intended use is not permitted by statutory regulation or exceeds the permitted use, you will need to obtain permission directly from the copyright holder. To view a copy of this licence, visit http://creativecommons.org/licenses/by/4.0/.

\section{References}

Papers of particular interest, published recently, have been highlighted as:

- Of importance

•• Of major importance

1. Tandon P, Low G, Mourtzakis M, Zenith L, Myers RP, Abraldes JG, et al. A model to identify sarcopenia in patients with cirrhosis. Clin Gastroenterol Hepatol. 2016;14(10):1473-80 e3.

2. Krell RW, Kaul DR, Martin AR, Englesbe MJ, Sonnenday CJ, Cai $\mathrm{S}$, et al. Association between sarcopenia and the risk of serious infection among adults undergoing liver transplantation. Liver Transpl. 2013;19(12):1396-402.

3. Periyalwar P, Dasarathy S. Malnutrition in cirrhosis: contribution and consequences of sarcopenia on metabolic and clinical responses. Clin Liver Dis. 2012;16(1):95-131.

4. Dasarathy S, Merli M. Sarcopenia from mechanism to diagnosis and treatment in liver disease. J Hepatol. 2016;65(6):1232-44 Excellent overview of the pathogenesis and future therapeutic targets of sarcopenia.

5. Lai JC, Rahimi RS, Verna EC, Kappus MR, Dunn MA, McAdamsDeMarco M, et al. Frailty associated with waitlist mortality independent of ascites and hepatic encephalopathy in a multicenter study. Gastroenterology. 2019;156(6):1675-82 Multi-centre study highlighting the ability of the Liver Frailty Index to predict mortality, irrespective of the degree of liver decompensation.

6. Kalafateli M, Mantzoukis K, Choi Yau Y, Mohammad AO, Arora $\mathrm{S}$, Rodrigues $\mathrm{S}$, et al. Malnutrition and sarcopenia predict post-liver transplantation outcomes independently of the Model for End-stage Liver Disease score. J Cachexia Sarcopenia Muscle. 2017;8(1): 113-21.

7. Dunn MA. The cost of sarcopenia. Transpl Int. 2018;31(2):155-6.

8. Sinclair M, Chapman B, Hoermann R, Angus PW, Testro A, Scodellaro T, et al. Handgrip strength adds more prognostic value to the model for end-stage liver disease score than imaging-based measures of muscle mass in men with cirrhosis. Liver Transpl. 2019;25(10):1480-7 Large multi-centre study highlighting that the addition of simple measure of hand grip strength to a liver disease severity model (MELD) aids with identifying patients with cirrhosis at great risk of death. 
9. Rosenberg IH. Summary comments. Am J Clin Nutr. 1989;50(5): 1231-3.

10. Cruz-Jentoft AJ, Bahat G, Bauer J, Boirie Y, Bruyere O, Cederholm $\mathrm{T}$, et al. Sarcopenia: revised European consensus on definition and diagnosis. Age Ageing. 2019;48(4):601.

11. Cruz-Jentoft AJ, Baeyens JP, Bauer JM, Boirie Y, Cederholm T, Landi F, et al. Sarcopenia: European consensus on definition and diagnosis: report of the European Working Group on Sarcopenia in Older People. Age Ageing. 2010;39(4):412-23.

12.• Carey EJ, Lai JC, Sonnenday C, Tapper EB, Tandon P, DuarteRojo A, et al. A North American expert opinion statement on sarcopenia in liver transplantation. Hepatology. 2019;70(5): 1816-29 Concise expert opinion on the key assessment tools and recommend managements strategies in patients withs sarcopenia awaiting liver transplantation.

13. Nam NH, Kaido T, Uemoto S. Assessment and significance of sarcopenia in liver transplantation. Clin Transpl. 2019;33(12).

14. van Vugt JLA, Levolger S, de Bruin RWF, van Rosmalen J, Metselaar HJ, Ijzermans JNM. Systematic review and metaanalysis of the impact of computed tomography-assessed skeletal muscle mass on outcome in patients awaiting or undergoing liver transplantation. Am J Transplant. 2016;16(8):2277-92.

15. Hanai T, Shiraki M, Imai K, Suetsugu A, Takai K, Moriwaki H, et al. Reduced handgrip strength is predictive of poor survival among patients with liver cirrhosis: a sex-stratified analysis. Hepatol Res. 2019;49(12):1414-26.

16. Cruz RJ Jr, Dew MA, Myaskovsky L, Goodpaster B, Fox K, Fontes $\mathrm{P}$, et al. Objective radiologic assessment of body composition in patients with end-stage liver disease: going beyond the BMI. Transplantation. 2013;95(4):617-22.

17. Montano-Loza AJ, Carey E, Ebadi M, Wang C, Dasarathy S, Kappus MR, et al. Skeletal muscle index indicates mortality risk more accurately than psoas muscle index in patients with cirrhosis. From the FLEXIT consortium. J Hepatol. 2018;68:S698-S9.

18. Carey EJ, Lai JC, Wang CW, Dasarathy S, Lobach I, Montano-Loza AJ, et al. A multicenter study to define sarcopenia in patients with end-stage liver disease. Liver Transpl. 2017;23(5):625-33.

19. Ebadi M, Wang CW, Lai JC, Dasarathy S, Kappus MR, Dunn MA, et al. Poor performance of psoas muscle index for identification of patients with higher waitlist mortality risk in cirrhosis. J Cachexia Sarcopenia Muscle. 2018;9(6):1053-62.

20. Kuo SZ, Ahmad M, Dunn MA, Montano-Loza AJ, Carey EJ, Lin S, et al. Sarcopenia predicts post-transplant mortality in acutely ill men undergoing urgent evaluation and liver transplantation. Transplantation. 2019;103(11):2312-7 4-centre study highlighting that Skeletal Muscle Index (defined cut-off) on CT imaging in patients upto 90 days before transplantation is predictive of post transplant mortality.

21. Montano-Loza AJ, Duarte-Rojo A, Meza-Junco J, Baracos VE, Sawyer MB, Pang JXQ, et al. Inclusion of sarcopenia within MELD (MELD-Sarcopenia) and the prediction of mortality in patients with cirrhosis. Clin Transl Gastroenterol. 2015;6(7):e102 e.

22. Giusto M, Lattanzi B, Albanese C, Galtieri A, Farcomeni A, Giannelli V, et al. Sarcopenia in liver cirrhosis: the role of computed tomography scan for the assessment of muscle mass compared with dual-energy X-ray absorptiometry and anthropometry. Eur J Gastroenterol Hepatol. 2015;27(3):328-34.

23. Hara N, Iwasa M, Sugimoto R, Mifuji-Moroka R, Yoshikawa K, Terasaka E, et al. Sarcopenia and sarcopenic obesity are prognostic factors for overall survival in patients with cirrhosis. Intern Med. 2016;55(8):863-70.

24. Morgan MY, Madden AM, Soulsby CT, Morris RW. Derivation and validation of a new global method for assessing nutritional status in patients with cirrhosis. Hepatology. 2006;44(4):823-35.
25. Alberino F, Gatta A, Amodio P, Merkel C, Di Pascoli L, Boffo G, et al. Nutrition and survival in patients with liver cirrhosis. Nutrition. 2001;17(6):445-50.

26. Doherty TJ. Invited review: Aging and sarcopenia. J Appl Physiol (1985). 2003;95(4):1717-27.

27. Ebadi M, Tandon P, Moctezuma-Velazquez C, Ghosh S, Baracos VE, Mazurak VC, et al. Low subcutaneous adiposity associates with higher mortality in female patients with cirrhosis. J Hepatol. 2018;69(3):608-16.

28. Montano-Loza AJ, Angulo P, Meza-Junco J, Prado CM, Sawyer MB, Beaumont C, et al. Sarcopenic obesity and myosteatosis are associated with higher mortality in patients with cirrhosis. J Cachexia Sarcopenia Muscle. 2016;7(2):126-35 Key study highlighting the importance of sarcopenic obesity and excess fat deposition in muscle in predicting the clinical outcomes of patients with cirrhosis.

29. Carias S, Castellanos AL, Vilchez V, Nair R, Dela Cruz AC, Watkins J, et al. Nonalcoholic steatohepatitis is strongly associated with sarcopenic obesity in patients with cirrhosis undergoing liver transplant evaluation. J Gastroenterol Hepatol. 2016;31(3):628-33.

30. Kamo N, Kaido T, Hamaguchi Y, Okumura S, Kobayashi A, Shirai $\mathrm{H}$, et al. Impact of sarcopenic obesity on outcomes in patients undergoing living donor liver transplantation. Clin Nutr. 2019;38(5): 2202-9.

31.• EASL. Clinical practice guidelines on nutrition in chronic liver disease. J Hepatol. 2019;70(1):172-93 Extensive evidence-based guideline of nutritional assessment and optimisation in patients with compensated and decompensated cirrhosis.

32.• Plauth M, Bernal W, Dasarathy S, Merli M, Plank LD, Schutz T, et al. ESPEN guideline on clinical nutrition in liver disease. Clin Nutr. 2019;38(2):485-521 Extensive evidence-based guideline of nutritional assessment and optimisation in patients with compensated and decompensated cirrhosis.

33. Lauretani F, Russo CR, Bandinelli S, Bartali B, Cavazzini C, Di Iorio A, et al. Age-associated changes in skeletal muscles and their effect on mobility: an operational diagnosis of sarcopenia. J Appl Physiol (1985). 2003;95(5):1851-60.

34. Kim B-J, Ahn SH, Lee SH, Hong S, Hamrick MW, Isales CM, et al. Lower hand grip strength in older adults with non-alcoholic fatty liver disease: a nationwide population-based study. Aging. 2019;11(13):4547-60.

35. Malinis MF, Chen S, Allore HG, Quagliarello VJ. Outcomes among older adult liver transplantation recipients in the model of end stage liver disease (MELD) era. Ann Transplant. 2014;19:478-87.

36. Tapper EB, Finkelstein D, Mittleman MA, Piatkowski G, Lai M. Standard assessments of frailty are validated predictors of mortality in hospitalized patients with cirrhosis. Hepatology (Baltimore, Md). 2015;62(2):584-90 One of the first studies highlighting the utility of Frailty Indices in patients hopsitalised with advanced liver disease.

37. Samoylova ML, Covinsky KE, Haftek M, Kuo S, Roberts JP, Lai JC. Disability in patients with end-stage liver disease: results from the functional assessment in liver transplantation study. Liver Transpl. 2017;23(3):292-8.

38. Lai JC, Feng S, Terrault NA, Lizaola B, Hayssen H, Covinsky K. Frailty predicts waitlist mortality in liver transplant candidates. Am J Transplant. 2014;14(8):1870-9.

39. Faustini-Pereira JL, Homercher-Galant L, Garcia E, de Mello Brandão AB, Marroni CA. Exercise capacity of cirrhotic patients with hepatopulmonary syndrome. Ann Hepatol. 2015;14(3):361-8.

40. Yadav A, Chang Y-H, Carpenter S, Silva AC, Rakela J, Aqel BA, et al. Relationship between sarcopenia, six-minute walk distance and health-related quality of life in liver transplant candidates. Clin Transpl. 2015;29(2):134-41.

41. Dunn MA, Josbeno DA, Tevar AD, Rachakonda V, Ganesh SR, Schmotzer AR, et al. Frailty as tested by gait speed is an 
independent risk factor for cirrhosis complications that require hospitalization. Am J Gastroenterol. 2016;111(12):1768-75.

42. Ney M, Haykowsky MJ, Vandermeer B, Shah A, Ow M, Tandon P. Systematic review: pre- and post-operative prognostic value of cardiopulmonary exercise testing in liver transplant candidates. Aliment Pharmacol Ther. 2016;44(8):796-806.

43. Bernal W, Martin-Mateos R, Lipcsey M, Tallis C, Woodsford K, McPhail MJ, et al. Aerobic capacity during cardiopulmonary exercise testing and survival with and without liver transplantation for patients with chronic liver disease. Liver Transpl. 2014;20(1):54 62.

44. Tandon P, Tangri N, Thomas L, Zenith L, Shaikh T, Carbonneau M, et al. A rapid bedside screen to predict unplanned hospitalization and death in outpatients with cirrhosis: a prospective evaluation of the clinical frailty scale. Am J Gastroenterol. 2016;111(12):175967.

45. Levett DZH, Jack S, Swart M, Carlisle J, Wilson J, Snowden C, et al. Perioperative cardiopulmonary exercise testing (CPET): consensus clinical guidelines on indications, organization, conduct, and physiological interpretation. Br J Anaesth. 2018;120(3):484-500.

46. Wijeysundera DN, Pearse RM, Shulman MA, Abbott TEF, Torres E, Ambosta A, et al. Assessment of functional capacity before major non-cardiac surgery: an international, prospective cohort study. Lancet. 2018;391(10140):2631-40 Highlights the importance of simple, subjective questionnaires, such as the Duke Activity Status Index, in predicting outcomes post major surgery. Needs validating in liver transplantation.

47. Fried LP, Tangen CM, Walston J, Newman AB, Hirsch C, Gottdiener J, et al. Frailty in older adults: evidence for a phenotype. J Gerontol A Biol Sci Med Sci. 2001;56(3):M146-56.

48. Williams FR, Berzigotti A, Lord JM, Lai JC, Armstrong MJ. Review article: impact of exercise on physical frailty in patients with chronic liver disease. Aliment Pharmacol Ther. 2019;50(9): 988-1000 Extensive overview and critical appraisal of the utility of hopsital and home-based exercise programs in patients with chronic liver disease.

49.• Lai JC, Covinsky KE, Dodge JL, Boscardin WJ, Segev DL, Roberts JP, et al. Development of a novel frailty index to predict mortality in patients with end-stage liver disease. Hepatology. 2017;66(2):564-74 The development of the first reproducible liver-specific frailty index (hand grip strength, balance, chairs stands) in predicting mortality in patients with end-stage liver disease. Needs validating in non-US countries.

50. Guralnik JM, Simonsick EM, Ferrucci L, Glynn RJ, Berkman LF, Blazer DG, et al. A short physical performance battery assessing lower extremity function: association with self-reported disability and prediction of mortality and nursing home admission. $\mathrm{J}$ Gerontol. 1994;49(2):M85-94.

51. Lai JC, Segev DL, McCulloch CE, Covinsky KE, Dodge JL, Feng S. Physical frailty after liver transplantation. Am J Transplant. 2018;18(8):1986-94.

52. Sinclair M, Poltavskiy E, Dodge JL, Lai JC. Frailty is independently associated with increased hospitalisation days in patients on the liver transplant waitlist. World J Gastroenterol. 2017;23(5):899-905.

53. Fozouni L, Mohamad Y, Lebsack A, Freise C, Stock P, Lai JC. Frailty is associated with increased rates of acute cellular rejection within 3 months after liver transplantation. Liver Transpl. 2019. https://doi.org/10.1002/lt.25669.

54. Lai JC, Sonnenday CJ, Tapper EB, Duarte-Rojo A, Dunn MA, Bernal W, et al. Frailty in liver transplantation: an expert opinion statement from the American Society of Transplantation Liver and Intestinal Community of Practice. Am J Transplant. 2019;19(7): 1896-906 Detailed expert opinion on the key assessment tools and recommend managements strategies in patients withs sarcopenia awaiting liver transplantation.
55. Norman K, Kirchner H, Lochs H, Pirlich M. Malnutrition affects quality of life in gastroenterology patients. World J Gastroenterol. 2006;12(21):3380-5.

56. Alvares-da-Silva MR, Reverbel da Silveira T. Comparison between handgrip strength, subjective global assessment, and prognostic nutritional index in assessing malnutrition and predicting clinical outcome in cirrhotic outpatients. Nutrition. 2005;21(2):113-7.

57. Bhanji RA, Moctezuma-Velazquez C, Duarte-Rojo A, Ebadi M, Ghosh S, Rose C, et al. Myosteatosis and sarcopenia are associated with hepatic encephalopathy in patients with cirrhosis. Hepatol Int. 2018;12(4):377-86

58. Montano-Loza AJ, Meza-Junco J, Baracos VE, Prado CMM, Ma M, Meeberg G, et al. Severe muscle depletion predicts postoperative length of stay but is not associated with survival after liver transplantation. Liver Transpl. 2014;20(6):640-8.

59. van Vugt JLA, Alferink LJM, Buettner S, Gaspersz MP, Bot D, Darwish Murad S, et al. A model including sarcopenia surpasses the MELD score in predicting waiting list mortality in cirrhotic liver transplant candidates: a competing risk analysis in a national cohort. J Hepatol. 2018;68(4):707-14.

60. DiMartini A, Cruz RJ Jr, Dew MA, Myaskovsky L, Goodpaster B, Fox K, et al. Muscle mass predicts outcomes following liver transplantation. Liver Transpl. 2013;19(11):1172-80.

61. Kaido T, Ogawa K, Fujimoto Y, Ogura Y, Hata K, Ito T, et al. Impact of sarcopenia on survival in patients undergoing living donor liver transplantation. Am J Transplant. 2013;13(6):1549-56.

62. Duarte-Rojo A, Ruiz-Margáin A, Montaño-Loza AJ, MacíasRodríguez RU, Ferrando A, Kim WR. Exercise and physical activity for patients with end-stage liver disease: improving functional status and sarcopenia while on the transplant waiting list. Liver Transpl. 2018;24(1):122-39.

63. Tandon P, Ismond KP, Riess K, Duarte-Rojo A, Al-Judaibi B, Dunn MA, et al. Exercise in cirrhosis: translating evidence and experience to practice. J Hepatol. 2018;69(5):1164-77.

64. Sgrò P, Sansone M, Sansone A, Sabatini S, Borrione P, Romanelli F, et al. Physical exercise, nutrition and hormones: three pillars to fight sarcopenia. Aging Male. 2019;22(2):75-88.

65. Kruger C, McNeely ML, Bailey RJ, Yavari M, Abraldes JG, Carbonneau $\mathrm{M}$, et al. Home exercise training improves exercise capacity in cirrhosis patients: role of exercise adherence. Sci Rep. 2018;8(1):99.

66. Tsien C, Garber A, Narayanan A, Shah SN, Barnes D, Eghtesad B, et al. Post-liver transplantation sarcopenia in cirrhosis: a prospective evaluation. J Gastroenterol Hepatol. 2014;29(6):1250-7.

67. Tsien C, Shah SN, McCullough AJ, Dasarathy S. Reversal of sarcopenia predicts survival after a transjugular intrahepatic portosystemic stent. Eur J Gastroenterol Hepatol. 2013;25(1):8593.

68. Jo Y, Linton JA, Choi J, Moon J, Kim J, Lee J, et al. Association between cigarette smoking and sarcopenia according to obesity in the middle-aged and elderly Korean population: the Korea National Health and nutrition examination survey (2008-2011). Korean J Fam Med. 2019;40(2):87-92.

69. Rom O, Kaisari S, Aizenbud D, Reznick AZ. Sarcopenia and smoking: a possible cellular model of cigarette smoke effects on muscle protein breakdown. Ann N Y Acad Sci. 2012;1259:47-53.

70. Schakman O, Kalista S, Barbe C, Loumaye A, Thissen JP. Glucocorticoid-induced skeletal muscle atrophy. Int J Biochem Cell Biol. 2013;45(10):2163-72.

71. Hammad A, Kaido T, Aliyev V, Mandato C, Uemoto S. Nutritional therapy in liver transplantation. Nutrients. 2017;9(10):1126.

72. Dhaliwal A, Towey J, Lord JM, Armstrong M, Elsharkawy AM. Nutrition in liver cirrhosis: a case-based overview. Frontline Gastroenterol. 2019. https://doi.org/10.1136/flgastro-2018-101121.

73. Palmese F, Bolondi I, Giannone FA, Zaccherini G, Tufoni M, Baldassarre $\mathrm{M}$, et al. The analysis of food intake in patients with 
cirrhosis waiting for liver transplantation: a neglected step in the nutritional assessment. Nutrients. 2019;11(10):E2462.

74. Haldar D, Kern B, Hodson J, Armstrong MJ, Adam R, Berlakovich $\mathrm{G}$, et al. Outcomes of liver transplantation for non-alcoholic steatohepatitis: a European Liver Transplant Registry study. J Hepatol. 2019; 71(2):313-22.

75. Cordoba J, Lopez-Hellin J, Planas M, Sabin P, Sanpedro F, Castro F, et al. Normal protein diet for episodic hepatic encephalopathy: results of a randomized study. J Hepatol. 2004;41(1):38-43.

76. Gluud LL, Dam G, Les I, Cordoba J, Marchesini G, Borre M, et al. Branched-chain amino acids for people with hepatic encephalopathy. Cochrane Database Syst Rev. 2015;9:CD001939.

77. Lai JC, Tandon P. How I Approach It: Improving nutritional status in patients with cirrhosis. Am J Gastroenterol. 2018;113(11):1574 6.

78. Mathur S, Janaudis-Ferreira T, Wickerson L, Singer LG, Patcai J, Rozenberg D, et al. Meeting report: consensus recommendations for a research agenda in exercise in solid organ transplantation. Am J Transplant. 2014;14(10):2235-45.

79. Garcia-Pagan JC, Santos C, Barbera JA, Luca A, Roca J, Rodriguez-Roisin R, et al. Physical exercise increases portal pressure in patients with cirrhosis and portal hypertension. Gastroenterology. 1996;111(5):1300-6.

80. Berzigotti A, Albillos A, Villanueva C, Genesca J, Ardevol A, Augustin S, et al. Effects of an intensive lifestyle intervention program on portal hypertension in patients with cirrhosis and obesity: The SportDiet study. Hepatology. 2017;65(4):1293-305 Key study $(n=60)$ highlighting that exercise and weight loss are safe in patients with cirrhosis and portal hypertension.

81. Morkane CM, Kearney O, Bruce D, Melikian C, Martin DS. An outpatient hospital-based exercise training programme for patients with cirrhotic liver disease awaiting transplantation: a feasibility trial. Transplantation. 2020;104(1):97-103.

82. Roman E, Garcia-Galceran C, Torrades T, Herrera S, Marin A, Donate $\mathrm{M}$, et al. Effects of an exercise programme on functional capacity, body composition and risk of falls in patients with cirrhosis: a randomized clinical trial. PLoS One. 2016;11(3):e0151652.

83. Zenith L, Meena N, Ramadi A, Yavari M, Harvey A, Carbonneau $\mathrm{M}$, et al. Eight weeks of exercise training increases aerobic capacity and muscle mass and reduces fatigue in patients with cirrhosis. Clin Gastroenterol Hepatol. 2014;12(11):1920-6 e2.

84. Williams FR, Vallance A, Faulkner T, Towey J, Kyte D, Durman S, et al. Home-based exercise therapy in patients awaiting liver transplantation: protocol for an observational feasibility trial. BMJ Open. 2018;8(1):e019298.
85. Nishida Y, Ide Y, Okada M, Otsuka T, Eguchi Y, Ozaki I, et al. Effects of home-based exercise and branched-chain amino acid supplementation on aerobic capacity and glycemic control in patients with cirrhosis. Hepatol Res. 2017;47(3):E193-200.

86. Krasnoff JB, Vintro AQ, Ascher NL, Bass NM, Paul SM, Dodd MJ, et al. A randomized trial of exercise and dietary counseling after liver transplantation. Am J Transplant. 2006;6(8):1896-905.

87. Moya-Najera D, Moya-Herraiz A, Compte-Torrero L, Hervas D, Borreani S, Calatayud J, et al. Combined resistance and endurance training at a moderate-to-high intensity improves physical condition and quality of life in liver transplant patients. Liver Transpl. 2017;23(10):1273-81 Highlights the need for both aerobic and resistance exercise post transplantation and the significant impact they can have on quality of life.

88. Moya-Najera D, Moya-Herraiz A, Gargallo P, Calatayud J, EscrigSos J, Colado JC. Clinical relevance of a balance training program on liver transplant patientsA Randomized Controlled Trial. Transplantation. 2019;103(5):965-72.

89. Corey RL, Whitaker MD, Crowell MD, Keddis MT, Aqel B, Balan $\mathrm{V}$, et al. Vitamin D deficiency, parathyroid hormone levels, and bone disease among patients with end-stage liver disease and normal serum creatinine awaiting liver transplantation. Clin Transpl. 2014;28(5):579-84.

90. Davuluri G, Krokowski D, Guan BJ, Kumar A, Thapaliya S, Singh D, et al. Metabolic adaptation of skeletal muscle to hyperammonemia drives the beneficial effects of l-leucine in cirrhosis. J Hepatol. 2016;65(5):929-37.

91. Sinclair M, Grossmann M, Hoermann R, Angus PW, Gow PJ. Testosterone therapy increases muscle mass in men with cirrhosis and low testosterone: a randomised controlled trial. J Hepatol. 2016;65(5):906-13 A potential key therapy for male patients with sarcopenia.

92. Ohara M, Ogawa K, Suda G, Kimura M, Maehara O, Shimazaki T, et al. L-Carnitine suppresses loss of skeletal muscle mass in patients with liver cirrhosis. Hepatol Commun. 2018;2(8):906-18.

93. White TA, LeBrasseur NK. Myostatin and sarcopenia: opportunities and challenges - a mini-review. Gerontology. 2014;60(4):28993.

94. Yoon MS. mTOR as a key regulator in maintaining skeletal muscle mass. Front Physiol. 2017;8:788.

Publisher's Note Springer Nature remains neutral with regard to jurisdictional claims in published maps and institutional affiliations. 